\title{
The Role of Business Management Training in Improving Enterprise Management Level
}

\author{
Hailin Wang \\ Rizhao Polytechnic, Shandong 276800, China. \\ rzwang2007@126.com
}

Keywords: Business administration training, improve, enterprise management level.

\begin{abstract}
With the trend of global economic integration becoming more and more obvious, enterprises are faced with various new opportunities and challenges in the process of development. In this case, it is of great significance for enterprises to improve their management level. From the actual situation, business management training can improve the level of enterprise management to a large extent, and make important contributions to the management of enterprises themselves and the cultivation of management personnel. This paper first expounds the connotation of business management training, analyzes the role of business management training in improving the level of enterprise management, and finally discusses how to use business management training to effectively improve the level of business management. Hope to produce reference significance in improving the level of enterprise management.
\end{abstract}

\section{Introduction}

Since China joined the World Trade Organization (WTO), the development trend of economic globalization has brought great market prospect for the development of our country's enterprises, at the same time, a lot of uncertain factors have been added. On the one hand, compared with the developed countries, most of the enterprises in our country are established late, and there are many deficiencies in the management experience and technology level, which makes it difficult to stand out in the fierce international market competition. On the other hand, a large number of multinational companies come into our country, to a large extent intensified the local market competition. In the process of development, enterprises should not only strengthen the introduction of advanced science and technology, but also strengthen their own talent management, improve the comprehensive quality of enterprise managers to meet all kinds of unpredictable challenges in the future. Based on the practical work experience, the author tries to discuss the role of business administration training in improving the management level of enterprises.

\section{Overview of Business Administration Training}

By definition, business administration training means that in order to improve the competitiveness of the enterprise itself, by strengthening the knowledge of finance, marketing, international business and economic law, the comprehensive quality of business administration personnel can be effectively enhanced. Strengthen the application of knowledge and methods in their own work to effectively in order to carry out economic management activities. With the continuous reform and deepening of the market economy in our country, if enterprises want to remain invincible in the fierce competition, they must conform to the trend of the development of the times and actively improve the comprehensive level of their own industrial and commercial administrators. Under the influence of planned economy for a long time, many enterprises in our country have many problems in management foundation, professional knowledge, management team and so on, which restrict the comprehensive development of enterprises to some extent. In view of this, actively conducting business management training helps to improve the overall quality of enterprise management team and achieve the economic and social value of enterprises. 
Business administration education was introduced into China in the early 1980s. After the reform and opening up, Deng Xiaoping proposed that the American government send management education experts to China for training, and the main object is enterprise management cadres. Subsequently, under the strong support of the government, China established the "Dalian Training Center for Industrial Science and Technology Management in China " , and became the first pilot of the first training base for industry and commerce. In 1984, China formally introduced the MBA system, and today, there are hundreds of colleges and universities offering MBA courses. The system of business administration education originated in the United States. After decades of continuous development and reform, the education system has been relatively perfect. With the continuous development and promotion of the global economy, business administration education is also advancing with the times which has become the enterprise senior management personnel training indispensable means.

From the point of view of the characteristics of business administration training, its goal is relatively clear, its main aim is to train senior management talents, it has a certain nature of vocational training, and it has definite application and practical guidance in training. In the training personnel selection, it usually need to have certain management experience, after the corresponding business administration training, personnel can return to the original management position. In terms of training content, because the training of business administration is mainly aimed at decision makers, it covers a wide range of management theories, but the depth is relatively insufficient, which emphasizes the maneuverability of the training content. In terms of training methods, business administration training needs to incorporate a large number of cases in the process of development, through practical simulation, role-playing method to carry out a series of teaching activities.

Since the reform and opening up, with the deepening of the market economy system, forming a situation that supply exceeds demand in many industries and fields. The socialist economic system with Chinese characteristics has been further established, and the competition among enterprises has intensified. In the process of survival and development of enterprises, it is not only facing the internal management problems of planned economy system, but also facing the pressure of debt, staff, and competition and so on. How to adapt to the market environment quickly becomes a problem that the government and entrepreneurs must face. With the introduction of various preferential policies one after another, the marketization of enterprise development becomes more obvious, coupled with the strong support of state policies. In the market competition, enterprises are constantly developing towards the direction of standardization and autonomy. Some enterprises have quickly stepped out of the predicament and got rid of all kinds of shackles of the planned economic system, but there are still a large number of enterprises go out of difficulties and not go out of danger, and they are struggling under the market economy competition. The introduction of business management training relieve the pressure that enterprises face to a certain extent alleviates. From the successful experience of western developed countries, professional managers can be competent for the management of enterprises at the senior level. These people often have received systematic business administration education who can play a good leading role in the professional quality and management level in the development of enterprises. However, not all enterprises are suitable for professional managers. For example, managers of state-owned enterprises are usually appointed by government departments, and managers who have received business administration education in the system required by enterprises cannot be filled from the high-end talent market. Therefore, business management training has become the best choice for business managers. According to the ability of the existing business schools in China to train the number of students, and the fact that these students need to be practiced for some time after graduation, the number of state-owned enterprise operators who have not received business administration training for a long time is quite large. In the face of fierce market competition, the management quality of state-owned enterprises needs to be improved. Through the training of business administration, the reasonable compression of the course and study time of business administration can effectively improve the management level and comprehensive quality of management personnel. 


\section{The significance of Business Administration training in Enterprises}

\subsection{The Promotion of the Professional Quality of the Enterprise Management Personnel.}

The importance of management talents in the survival and development of enterprises is self-evident. Judging from the nature of many enterprises in our country, there are more private and familial talents, and most of these management talents are not of high professional quality. Some people believe that by their own economic strength and family background to achieve good business management, which restricted the long-term development of enterprises to a large extent .Through the training of business administration and strengthening the education of comprehensive economic management theory knowledge, the comprehensive quality of enterprise management talents can be improved to a great extent, and the ability of management to schedule the overall situation can be strengthened to a great extent. In addition, the improvement of management professional quality and management level can also play a good leading role, promote the enthusiasm of enterprise staff and workers to learn, form a good atmosphere, and promote the overall development of enterprises.

\subsection{Helping Enterprises Adapt to Market Changes.}

In the present era of global integration, the globalization of economic and trade in the future is an inevitable development trend. Since China's entry into WTO in 2003, the development of Chinese enterprises has been in line with the world, and the market economy has changed smoothly. With the increasingly fierce competition in the international market, enterprises all over the world are looking for a new path suitable for their own development. Facing the cruel market competition environment, how to conform to the market change, stand out in many international enterprises has become the focus of attention. On the one hand, through the business management training to seek the breakthrough and promotion of enterprise management level, through scientific, reasonable, targeted training, according to the basic needs of the development of international market, make the innovation management knowledge of the times and the way of training through the mind of enterprise managers, can effectively improve the comprehensive strength of enterprise managers to develop and expansion in the fierce market competition in the continuous .

\subsection{Contribute to A Better Understanding of the Operational Mechanisms of the Current} Market Economy by Enterprise Management.

The environment of market economy is complex and changeable. In the process of survival and development of enterprises, it is necessary to have a deep understanding of the operating mechanism of the current market economy. Through the training of business administration, we can effectively enhance the comprehensive analysis ability of enterprise managers. Scientific and reasonable way to understand the market operation mechanism to promote the coordinated development of the enterprise itself. In the process of continuous development and expansion, it is an effective guarantee to improve the level of business administration and the smooth development of all kinds of work in the process of continuous development and expansion of the current competitive market mechanism of enterprises in our country. This paper makes rational use of the knowledge of business administration training and analyzes the restrictive factors in the process of enterprise development so as to have a deeper understanding of the current market operation mechanism and speed up the process of enterprise modernization and all-round development.

\subsection{Innovation and Change of Business Management Mode.}

Due to the influence of historical conditions and market environment, the development of Chinese enterprises is greatly influenced by the traditional management mode. With the acceleration of the development trend of global economic integration, the traditional management mode cannot meet the needs of the current development of the international market economy. In view of this situation, enterprises should speed up the strategic transformation and adjust their own management structure, according to the development needs of the market economy, while inheriting the traditional management mode and constantly reforming and innovating. Open up a new mode of economic development for socialist enterprises with Chinese characteristics. From the practical effect, it is undoubtedly the best choice to strengthen the business administration training of enterprises, which can effectively promote the idea of enterprise management innovation, inject continuous vitality into 
the development of enterprises, and thus lay the foundation for the development of enterprises in the international market.

\section{Problems existing in the process of Business Administration training of Enterprises}

\subsection{Insufficient Attention.}

According to the actual situation of many enterprises' business administration training, most of them adopt streamline operation method, and the formalization is more serious, which makes it difficult to carry out all kinds of work of business administration training. From the point of view of the enterprise's own development, the lack of attention to the training of business administration will cause the development of all kinds of work cannot be carried out, and the weakness of this awareness is more obvious in the small and medium-sized enterprises. In the process of enterprise development, the management will spend more energy on the development and growth of the enterprise and the promotion of economic benefits, and is unwilling to spend too much time and money on the business administration training. Judging from the actual situation, many enterprises spend fewer times to carry out business administration training, and some enterprises even give up directly. Lacking relatively complete business administration training programs, which often result in enterprises receiving financial and human resources for business administration training. Many factors, such as material resources, restrict the training activities of business administration, which are difficult to carry out efficiently and normally, and the actual training work is difficult to achieve the ideal training effect, which to a great extent limits the improvement of the overall management level of the enterprise.

\subsection{The Team of Training Faculty for Business Administration Needs to Be Improved.}

From the actual situation of enterprise business administration training, because of the late start, most enterprises' training in this field is still in the initial stage. In the management system, there is a lack of systematic and large-scale development model. The reason for this is mainly due to the lack of teachers within the enterprise. Compared with the enterprise training method, the business administration training has the very prominent characteristic, such as it needs the higher request for the training instructor, not only the higher theory knowledge, but also the very strict request to its educational background, the practice experience and so on. In order to reduce the expenditure on business administration training, some enterprises often fail to meet the basic needs of business administration training in the selection of trainers, and the overall training effect falls short of the expected requirements. The theoretical knowledge and professional quality of enterprise managers cannot be effectively promoted, and the training of business administration is a mere formality.

\subsection{Single Training Model.}

In the mode of business administration training, many enterprises still stay in the traditional management method, lack effective propaganda of training consciousness, lack of attention to business management training by the enterprise managers who participate in the training, and do not take an active attitude in the actual training process. Some managers are only for the task arranged by the enterprise and lack of subjective initiative in the study and practice of theoretical knowledge. Some managers even only want to get the relevant training certificate and give their own gold deposit. The development of the market economy is changing, the traditional enterprise management mode can no longer meet the development needs of the current stage, and the contents and methods of management need constant reform and innovation, which puts forward higher requirements for the personnel involved in the training of business administration. We should not only take the initiative in thinking, but also strengthen the practicability of the knowledge of business administration in the daily management of enterprises, provide a large number of cases and materials for the training work, and improve the level and efficiency of solving practical problems for managers. In addition, after the training, enterprises should strengthen the evaluation and evaluation of business management training to ensure the practicability and effectiveness of business management training. In the way of examination, not only the theoretical knowledge, but also the practical application ability should be paid more attention to, and the enthusiasm and the overall effect of participating in the business 
administration training personnel should be improved. When enterprises conduct business administration training, they need to distinguish it from the traditional training mode. The training effect of business administration training cannot be tested according to the traditional examination mode, and the practical effect cannot be brought into play under the traditional appraisal mode, and the practical significance of business administration training will be lost.

\section{Strategies to Improve the Effect of Business Administration Training in Enterprises}

\subsection{Enhanced the Emphasis.}

Strengthening enterprises' attention to business management training, it should begin with enterprise leadership, which is directly related to the execution and training effect of business management training, and provide decision support for related business management trainers. On the one hand, in the daily management of enterprise propaganda activities, it is necessary to strengthen the propaganda of business management training knowledge and strengthen enterprise management. The understanding of the importance of business management training, mobilizing managers to participate in the enthusiasm of business management training, and linking business management training with the survival and development of enterprises, which will be used as an important development process in the development planning of the enterprise. On the other hand, it is necessary to strengthen the understanding of the importance of business management training among all the staff and workers of the enterprise, put an end to formalism, and link business administration training with the economic benefits of the enterprise and the welfare and treatment of the workers and staff. Through the relevant propaganda activities and training and education to make employees to establish the correct concept of business management training which ensure the effective implementation of business management training.

\subsection{Strengthen the construction of training team.}

Pay attention to the promotion of business administration training teachers, and provide reliable training team for the development of training work. Establish relatively perfect standards for the audit of trainers, and conduct a comprehensive assessment of the trainers' theoretical knowledge, practical experience, ideological and political quality, etc. in the training of business administration. To ensure that the overall quality of business management training teachers that could meet the basic requirements of enterprise training. After the examination and recruitment of business administration trainers, we should strengthen the exchange and cooperation between trainers and similar enterprises, pay attention to professional knowledge and promotion, and inject a continuous stream of vitality into business administration training. At the same time, we have a good grasp of the recent development and development of business management, and actively enrich the experience of business management training. In the development of the enterprise, we should continuously introduce excellent talents of business administration training, pay attention to the establishment of the teaching staff of business administration, such as different specialties, practical experience and theoretical knowledge, so as to lay a solid foundation for the long-term and stable development of the enterprise. For example, in order to improve the overall level of business administration in enterprises, a joint training agreement can be reached with teachers majoring in business administration in colleges and universities. Pay attention to the dual improvement of theoretical knowledge and practical experience.

\subsection{Enhanced Training Content and Modalities.}

From the practical effect, the traditional content and method of business administration training cannot meet the actual needs of the current stage of the development of enterprises, enterprises put forward higher requirements for business management training. In terms of the contents and methods of business management training, enterprise leaders, trainers and managers involved in training should recognize the current situation of enterprise development and pay attention to the effectiveness and maneuverability of training. With the continuous development of Internet technology and information technology, diversified business management training content and mode has become an important development trend. With the penetration of information technology, 
business management training must keep pace with the times, give full play to the advantages of information resources, and optimize the methods of business management training through multimedia, Internet and other technologies. In the process of training, the trainers should change the traditional monotonous training methods, improve the enthusiasm of the participants through the use of group competitions, video cases and so on, so that the relevant personnel have a deep understanding of business administration training. In addition, the trainers should attach great importance to the training and guidance of business management theory, strengthen the importance of business management theory in practical work, and encourage participants to combine theory and practice. Thus, strengthening the content and ways of business management training, to enhance the level of comprehensive management of enterprises is of great significance.

\subsection{Develop Relatively Perfect Training Plans.}

First of all, we should do well before the training. The senior leaders of the enterprise should give full affirmation to the status of the trainers and provide effective support for the training of business management. Before the start of the training, the trainers should have sufficient grasp of the contents of the training, adjust the training method and content in time, collect and organize the training materials to ensure the training. Therefore it is well documented. In terms of training methods, it can learn from the training experience of similar enterprises in business administration, so as to make it clear and clear. At the same time, we should constantly perfect the training content, adjust the training plan reasonably according to the actual situation of the market development in the current stage, and promote the virtuous circle of the enterprise. Secondly, to strengthen the timely feedback of the training content, to make reasonable judgment on the application and operability of the training results, and to strengthen the comprehensive application ability of the trained personnel to the knowledge through theoretical evaluation and practical case analysis. Improve the practical application of business administration training.

\subsection{Increase in the Total Class Hours and the Content of the Training.}

In the course of business management training, because the participants are mainly the enterprise management, in view of the particularity and importance of the management work, the training time is short, and the content and depth of the training cannot reach the ideal state. In this case, the business management training often fails to reach the expected requirements. Therefore, enterprises should pay attention to increase the total hours and contents of business administration training, enhance the breadth and depth of training, pay attention to classroom teaching, case analysis, computer operation, group exercises and after-school homework integrated arrangements. The course schedule should be based on the actual situation of the enterprise, such as information management, electronic commerce and international business courses should be arranged in the form of a series of special events. This is mainly due to the fact that middle-aged managers are the majority of business managers, who are relatively weak in terms of information management, e-commerce and international business knowledge. Arranging special lecture series can reduce the difficulty of learning and make up for the deficiency of managers' knowledge.

\subsection{Improve the Assessment Mechanism for Trainees.}

From the actual situation, most enterprises take the initiative to provide management with the opportunity for further education, theoretically speaking, systematic business management training is conducive to the improvement of the overall management level of enterprises, but the actual results are often not satisfactory. The reason is that many enterprise managers regard business management training as an opportunity for tourism rest, lack of clear learning goals, and a serious idea of poor learning, which results in unsatisfactory overall training results. In view of this situation, enterprises should establish a training assessment mechanism for trainees, and clearly position the objectives, significance and assessment methods of business administration training. Let the training personnel fully realize that this is an opportunity to improve their professional quality and overall management level, so as to enhance the enthusiasm and overall effect of business administration training for managers.

In the examination mechanism of business administration training, we should pay attention to the following aspects: on the one hand, the examination of theoretical knowledge, strengthening the 
study of systematic theoretical knowledge and the application of practice. Paying attention to the combination of theory and practice. Guiding practice with theory, deepening theory in practice, realizing the common improvement of theoretical knowledge and practical ability; on the other hand, after training, trainees should sum up management methods, analyzes the shortcomings and advantages of the management methods in the development process of enterprises, and puts forward some reasonable improvement methods, so as to learn from each other's weaknesses and draw on the new. In addition, the training assessment mechanism should pay attention to the evaluation of emotional attitude, make a comprehensive evaluation of the attitude, the positive degree, the ideological understanding, the spirit of teamwork, and so on. Improving the working attitude, thinking level and team cohesion of enterprise managers through business management training is helpful to improve the comprehensive management level of enterprises.

\section{Summary}

In short, with the fierce competition among enterprises in the world, in the process of the development of enterprises, we should attach great importance to the training of business administration, change the traditional ideas in time, and pay attention to the effectiveness of the training of business administration. Cultivate a group of high-quality professional management talents for the development of enterprises, ensure that enterprises in the fierce market competition in an invincible position. After the training, the managers should sum up the problems existing in the development of the enterprise in time, put forward the targeted improvement strategy, and optimize the overall development goal of the enterprise. Only in this way can the practical effect of business administration training be brought into full play, the whole management level of enterprises be improved, and the economic and social value of enterprises be realized.

\section{References}

[1]. Jiang Hailing, Li Xinyang. How to strengthen the training of Business Administration and improve the level of Enterprise Management [J]. Science and Wealth 2017 (28): 178-178.

[2]. Wu Po-Zhao. On the role of Business Administration training in improving the Management level of Enterprises [J]. China Business \& Trade 2014 (9): 26-27.

[3]. Li Xin. Study on the role of Business Administration training in improving the level of Enterprise Management [J]. Store Modernization 2015 (5): 114-115.

[4]. Fang Ming. How to strengthen the training of Business Administration and improve the level of Enterprise Management [J]. Contemporary Educational practice and Teaching Research 2016 (09): 88.

[5]. Zeng Zhongwei, Ye Jeanie, Bai Xia. Suggestions for strengthening the training of business administration in enterprises [J]. Shenmue technology, 2013, 11 (03):15-16+34.

[6]. Liu Yandi, Li Hailie. The influence of Business Administration training on the improvement of Enterprise Management level [J]. Management Watch 2014 (21): 109-110.

[7]. Xu Tina. A brief talk on how to improve the level of Enterprise Management by strengthening the training of Business Administration [J]. A theoretical study of Commodity and quality 6 (8): 12-13.

[8]. Wang Young, Yang Yuan. Study on the significance and Countermeasures of Business Administration training in improving Enterprise Management level [J]. The mall is modernized by 2016 01: 72-73. 
[9]. Dial Shaming. This paper discusses how to strengthen the training of business administration to improve the overall management level of enterprises [J]. Research on Modern State-owned Enterprises: 022: 51.

[10]. Liu Jibe. How to strengthen the business management training to improve the overall management level of enterprises [J]. Business managers 28: 208. 